\title{
Performance and Design Study of Optimized LNG Mixed Fluid Cascade Processes
}

\author{
Eivind Brodal*, Steve Jackson and Oddmar Eiksund \\ UiT-The Arctic University of Norway
}

\section{Abstract}

Mixed Fluid Cascade (MFC) processes are often claimed to be one of the most efficient methods to liquefy natural gas. Their performance depends on both operating conditions such as ambient temperature, and system design parameters such as exchanger sizes. The performance of the standard MFC process can be further improved by modifying the design with additional equipment, such as liquid refrigerant expanders or additional pressure levels in the refrigerant cycles.

This article presents a performance study of several modified MFC processes. Results are obtained using multivariable optimization algorithms in MATLAB and a process model developed in HYSYS. Constraints related to minimum internal temperature approach are used to model the main heat exchangers. The results illustrate the impact of ambient temperature on performance, and that modifications with either two-stage pre-cooling systems or liquid expanders reduce the power consumption by $3.0 \%-4.5 \%$, translating into a $15 \%-30 \%$ reduction in the combined UA values of the main heat exchangers.

\section{Keywords}

MFC; Optimization; Expander; Ambient temperature; LNG

* Corresponding author. Tel.: (+47) 77660364. E-mail: eivind.brodal@uit.no

\section{Nomenclature}

\begin{tabular}{|c|c|c|c|}
\hline$g$ & constraint function [-] & \multicolumn{2}{|c|}{ Subscripts \& Superscripts } \\
\hline$h$ & specific enthalpy [kJ/kg] & dew & dew point \\
\hline$k$ & penalty factor [-] & Ex & expander \\
\hline$m$ & mass [ton] & $\mathrm{K}$ & compressor \\
\hline$\dot{m}$ & mass flow [ton/h] & $\mathrm{amb}$ & ambient \\
\hline$\eta$ & isentropic efficiency [-] & av & average \\
\hline$n$ & molar fractions [\%] & \multicolumn{2}{|c|}{ Abbreviations } \\
\hline$p$ & pressure [bar] & LNG & liquefied natural gas \\
\hline$Q$ & heat [kJ] & MFC & mixed fluid cascade \\
\hline$q$ & penalty function [kWh/ton NG] & MR & mixed refrigerant \\
\hline$r$ & pressure ratio [-] & NG & natural gas \\
\hline$T$ & temperature $\left[{ }^{\circ} \mathrm{C}\right]$ & \multirow{5}{*}{\multicolumn{2}{|c|}{ 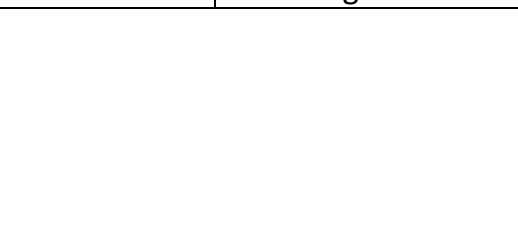 }} \\
\hline$U A$ & LNG exchanger(s) UA value $\left[\mathrm{Wh} /\left({ }^{\circ} \mathrm{C}\right.\right.$ ton $\left.\left.\mathrm{NG}\right)\right]$ & & \\
\hline$W$ & electrical power [kWh] & & \\
\hline$w$ & specific electrical power [kWh/ton NG] & & \\
\hline$X$ & vapor fraction [-] & & \\
\hline
\end{tabular}




\section{Introduction}

The natural gas industry is expanding, and is likely to produce $37 \%$ of the world's fossil fuel-based electrical power production by $2030[1,2]$. When transportation of natural gas (NG) through a pipeline is not economically attractive, it is typically liquefied and transported using ships or trucks. NG obtains a high density at atmospheric pressure if it is cooled to approximately $-160^{\circ} \mathrm{C}$ and liquefied. Production of liquefied natural gas (LNG) is a cost and energy-intensive process, which worldwide releases a considerable amount of $\mathrm{CO}_{2}$ because the refrigeration process is typically powered by gas turbines. The LNG plant at Melkøya in Northern Norway, for example, releases yearly almost $10^{9} \mathrm{~kg}$ of $\mathrm{CO}_{2}$, which is nearly $2 \%$ of Norway's total $\mathrm{CO}_{2}$ emissions [3]. However, LNG is still often viewed as an environmentally friendly energy source in a transition period between fossil fuel and renewable energy, because $\mathrm{CO}_{2}$ emissions from LNG production represent only a small percentage of the total emission in the gas to power chain [4]. Overall, the total $\mathrm{CO}_{2}$ footprint from an LNG based power chain is significantly less than power generation from coal. For example, gas turbines and combined cycle gas turbine (CCGT) plants that burn natural gas emit around 0.594 and $0.436 \mathrm{~kg}\left(\mathrm{CO}_{2}\right) / \mathrm{kWh}$, respectively, while coal power plants emit around $0.915 \mathrm{~kg}\left(\mathrm{CO}_{2}\right) / \mathrm{kWh}[5]$.

The liquefaction process is the most expensive and energy consuming part in the LNG supply chain, and much effort has therefore been put into optimizing the refrigeration process [2]. The mixed-fluid cascade (MFC) process was developed by Linde in collaboration with Statoil and used at Melkøya, and is one of the most energy efficient LNG plants in the world [6]. Melkøya is located in the Arctic, therefore the LNG plant efficiency also benefits from the low ambient temperature. Although ambient temperature is important to the overall energy efficiency, a limited number of studies discuss this aspect for MFC processes [4, 7], and the papers identified only study the standard MFC process.

The main focus of this article is to present detailed and accurate results illustrating how the performance of a standard MFC process and modified MFC processes depend on the ambient temperature. MFC is a process with three mixed refrigerant (MR) cycles combined in a cascade. The three cycles are divided into pre-cooling, liquefaction, and sub-cooling. The MFC process is complex, including a large number of design parameters which affect performance, for example, concentrations of the three different of mixed refrigerants, compressor efficiencies, number of heat exchangers with cooling water, heat exchanger sizing, etc. The standard MFC process can be modified to reduce energy consumption. Ding et al. present different relevant pre-cooling modifications, but do not discuss ambient temperature sensitivity for the modified processes [7]. The benefit realizable by replacing conventional Joule-Thompson (JT) valves with expanders has been discussed for single mixed refrigerant (SMR) process by Qyyum et al. in 2018 [8], but this technology has not been studied in the context of a MFC process.

For an LNG process to be thermodynamically efficient, it is important to minimize the temperature approach inside each heat exchanger. However, models of real exchangers include a large number of variables (design, length, area, material), which are difficult to implement in an optimization study of a system as complex as a MFC plant. Hence, simplified models are used in this study to estimate the optimal process values through multivariable performance optimization, based on the assumption that the heat exchangers are optimized for the given set of operating conditions. The most common approach to modeling optimal MFC processes is to reduce the number of system variables through the application of a set of realistic process constraints such as modelling the heat exchangers with a minimum allowed temperature pinch, as was introduced by Jensen et al. in 2006 [9]. The assumption being that heat exchangers with similar temperature pinch are similar in size, even though conditions like the compositions of the mixed refrigerants may vary. That is, the temperature profile inside each 
exchanger directly relates to the system design cost. Reasonable temperature pinch constraints used for LNG processes are typically 2-3 K [10]. The pinch constraints used in this study are implemented with a penalty method, using the method explained by Ding et al. (2017) [7].

In theory, it is desirable to compare MFC process performance with optimal heat exchanger designs with a fixed total life cycle cost for the LNG plant. The minimum temperature pinch analysis, gives a good indication of the best heat exchanger sizing, since it provides a target which can be used in post process calculations to evaluate heat exchanger design, size and capital cost, which are key parameters when designing a plant. The optimized data may also be further improved by modifying the temperature pinch requirement while keeping other optimized variables unchanged, like the composition of the different refrigerants. For example, using heat exchanger UA values calculations to optimize LNG process [11]. The assumption being that the $U A$ value can, to some extent, be used to compare heat exchangers with the same area $A$ (and cost), i.e. suitable to compare processes with only small variations where the heat transfer coefficient $U$ can be expected to be similar.

Jensen and Skogstad published the first optimized data for the MFC in 2006 [9]. In 2014, Austbø et al. published an annotated bibliography, identifying 186 published works on LNG process performance. Of the 186 works, Austb $\varnothing$ et al. identified seven related to MFC, but most of these articles did not include optimization work, and only one is included in the LNG optimization review article by Qyyum et al. in 2018 [12]. Other review articles with a focus on design and optimization of LNG processes are recently published by Khan et al. in 2017 [13], and by He et al. in 2018 [14]. These reviews show that most of the LNG optimization studies have been published in the last five years. In 2014, Mehrpooya et al. compared MFC, C3-MR and DMR system performances [6], and in 2016 they studied an MFC related process based on an absorption refrigeration system using waste heat as energy source [15]. In 2015, Austb $\varnothing$ published a doctoral thesis discussing optimization, and optimized data for MFC plants and related systems with fewer cascade cycles [16]. Ghorbani et al. optimized a MFC process including a nitrogen remove unit in 2016 [17], and studied LNG/NGL recovery process using absorption in 2018 [18]. Ding et al. published a MFC sensitivity study in 2017, investigating feed gas pressure, LNG storage pressure, water-cooler temperature, as well as the gain obtained by improving the one-stage pre-cooling cycle with two and three pressure levels [7].

Overall, there are only a few MFC optimization studies, and none of them have directly discussed the importance of designing processes with only internal pinches in the main heat exchangers. Some LNG articles modeling mixed refrigerants present results showing that optimized systems do not operate with a temperature pinch at the natural gas streams outlets of the heat exchangers $[8,9,19]$, while others do $[7,20,21]$. Literature based on manual optimization of MFC process performance parameters often uses simplified and inaccurate assumptions, e.g. that the minimum temperature approach is located at the outlet of the LNG exchangers [4, 22], which is often easy to set as a condition in the available process modelling packages. To understand the importance of how the pinch is specified, this article investigates the loss in performance if the natural gas streams at the outlet of the heat exchangers are defined at minimum allowed temperature pinch. As a consequence, this study is also the first to directly optimize the temperature differences at the end of the exchangers.

Only two MFC sensitivity studies on ambient temperature have been published [4, 7], and both of these sensitivity studies only investigated systems with one-stage pre-cooling cycle. Ding et al. [7] explored a small interval of ambient temperatures, which relates to the results presented in this article for ambient temperature between $27^{\circ} \mathrm{C}$ and $39^{\circ} \mathrm{C}$. Ding et al. [7] also did not optimize the NG temperature between the LNG heat exchangers, but assumed that these were constant. Ding et al. used a simplified optimization procedure where each refrigeration cycle was optimized individually in 
a sequence from the sub-cooling cycle to the pre-cooling cycle. Jackson et al. [4] optimized parameters manually in HYSYS based on optimized data from Jensen et al. [9].

The scope of this study is to investigate more complex MFC processes, including a two-stage cycle, and to evaluate and present energy efficient process parameters at different ambient temperatures. The actual trade-off between energy consumption and LNG heat exchanger sizes related to capital costs is also investigated by studying the optimized process parameters with respect to the $U A$ values of the LNG heat exchangers.

\section{Method}

This chapter presents modeling assumptions, defines the standard MFC case and the modified MFC processes, and explains the method used to search for the best design configuration for different ambient temperatures $\left(T_{\mathrm{amb}}\right)$. The text includes a description of the process model developed in HYSYS, the multivariable optimization approach used to obtain the best operational parameters, and the simplified reoptimization model comparing processes with respect to $U A$ values.

\subsection{System Design and Process Modelling}

Three different MFC design cases referred to as A, B and C are modelled in this study. Figure 1 presents the flowsheet of the standard MFC design that forms the basis in this performance study (case A), and the modifications used in case B and C. All the designs have six compressors ("K"), and use maximum six seawater coolers. Case A has three main LNG heat exchangers ("LNG pre-cooler", "LNG condenser" and "LNG sub-cooler").

The standard MFC design is optimized for two cases ( $A$ and $A^{*}$ ), where the only difference is how the outlet natural gas steam temperatures ( $T_{\text {MR1-7 }}, T_{\text {MR2-8 }}$ and $\left.T_{\text {MR3-9) }}\right)$ are defined. For case $A^{*}$ they are defined directly in the process model through external temperature pinches located at the end of the heat exchangers, while in case $A$ they are optimized using constraints allowing internal temperature pinches. Both case $B$ and $C$ have modified the "LNG pre-cooler" with a two-stage pre-cooler circuit ("LNG pre-cooler-A" and "LNG pre-cooler-B"), as illustrated in Figure 1. Case C is also modified by adding liquid expanders ("Ex") to reduce the thermodynamical loss related to the three conventional JT valves, however, valves are still required if the expanders only are allowed to operate with refrigerants in the liquid phase. The natural gas specifications used in this article are listed in Table 1.

Table 1. Natural gas specifications.

\begin{tabular}{|c|c|c|}
\hline Property & Unit & Value \\
\hline Pressure $\left(p_{\mathrm{NG1}}\right)$ & bar & 60 \\
\hline Temperature $\left(T_{\mathrm{NG} 1}\right)$ & ${ }^{\circ} \mathrm{C}$ & $T_{\mathrm{amb}}+3$ \\
\hline Temperature $\left(T_{\mathrm{LNG}}\right)$ & ${ }^{\circ} \mathrm{C}$ & -156 \\
\hline NG composition: $\mathrm{i}-\mathrm{C}_{4} \mathrm{H}_{8}$ & $\mathrm{~mol} \%$ & 0.40 \\
\hline $\mathrm{n}-\mathrm{C}_{4} \mathrm{H}_{8}$ & $\mathrm{~mol} \%$ & 0.80 \\
\hline $\mathrm{C}_{3} \mathrm{H}_{8}$ & $\mathrm{~mol} \%$ & 2.60 \\
\hline $\mathrm{C}_{2} \mathrm{H}_{6}$ & $\mathrm{~mol} \%$ & 5.40 \\
\hline $\mathrm{CH}_{4}$ & $\mathrm{~mol} \%$ & 87.70 \\
\hline $\mathrm{N}_{2}$ & $\mathrm{~mol} \%$ & 3.10 \\
\hline
\end{tabular}

\subsubsection{HYSYS Process Model}

All MFC processes are modelled in HYSYS using the SRK fluid package. Aspen HYSYS, is a graphical simulation tool, and is currently the most popular software for process modelling and simulation of LNG units [23]. Initially, a model of the standard MFC design was developed in HYSYS and verified with the optimized design parameters proposed by Jensen et al. [9]. 
The flowsheets presented in Figure 1 are simplified images of the HYSYS model, since the HYSYS model is set-up to enable inputs from MATLAB such as the molar fractions $n$ of each pure components and the temperature difference $\Delta T$ at the outlet of the LNG exchangers:

$$
\begin{aligned}
& \Delta T_{\mathrm{MR1-7}}=T_{\mathrm{NG2}}-T_{\mathrm{MR1}-7}, \\
& \Delta T_{\mathrm{MR2}-8}=T_{\mathrm{NG3}}-T_{\mathrm{MR2-8}} \\
& \Delta T_{\mathrm{MR3-9}}=T_{\mathrm{LNG}}-T_{\mathrm{MR3}-9,} \\
& \Delta T_{\mathrm{NG2a}}=T_{\mathrm{NG2a}}-T_{\mathrm{MR1-6c}}
\end{aligned}
$$

which are suitable parameters for optimizing, since the $\Delta T$ range typically only is a few degrees.

$\underline{\text { Case } A \text { and } A^{*}}$

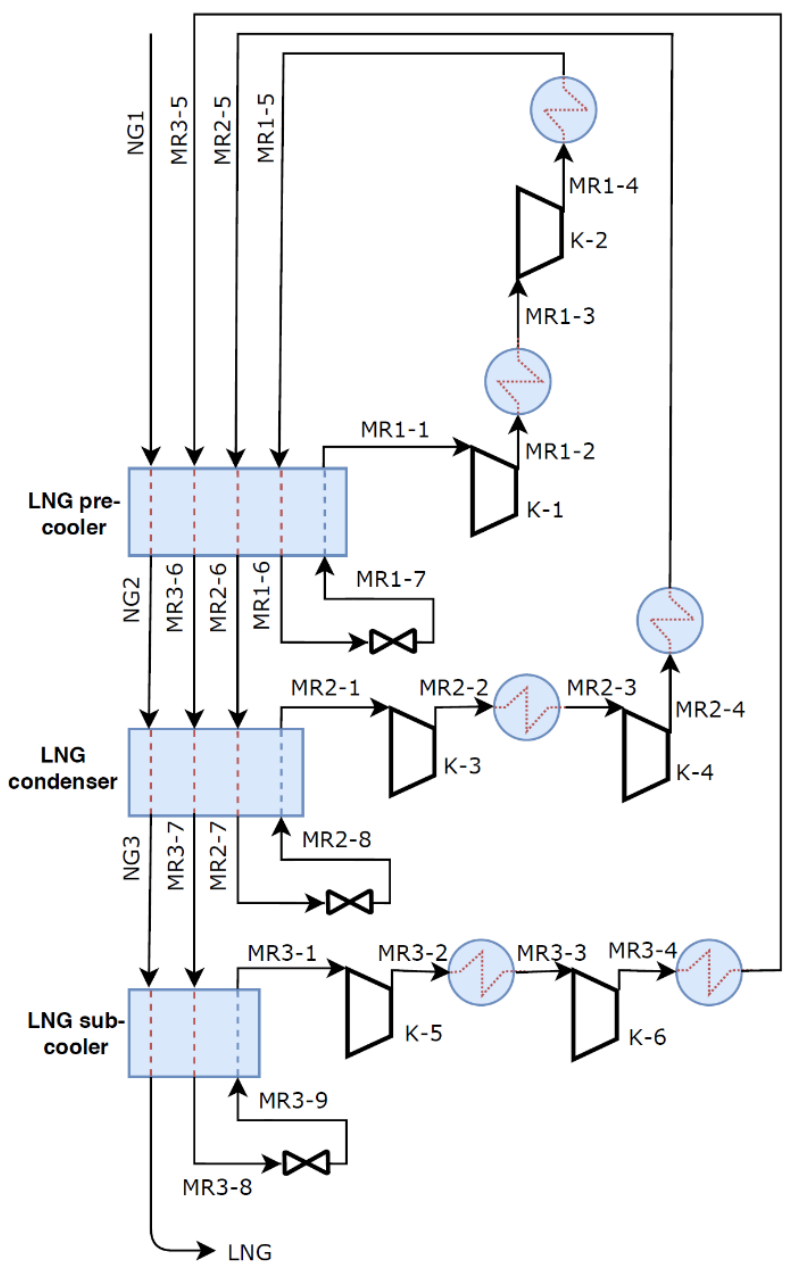

$\underline{\text { Case B }}$

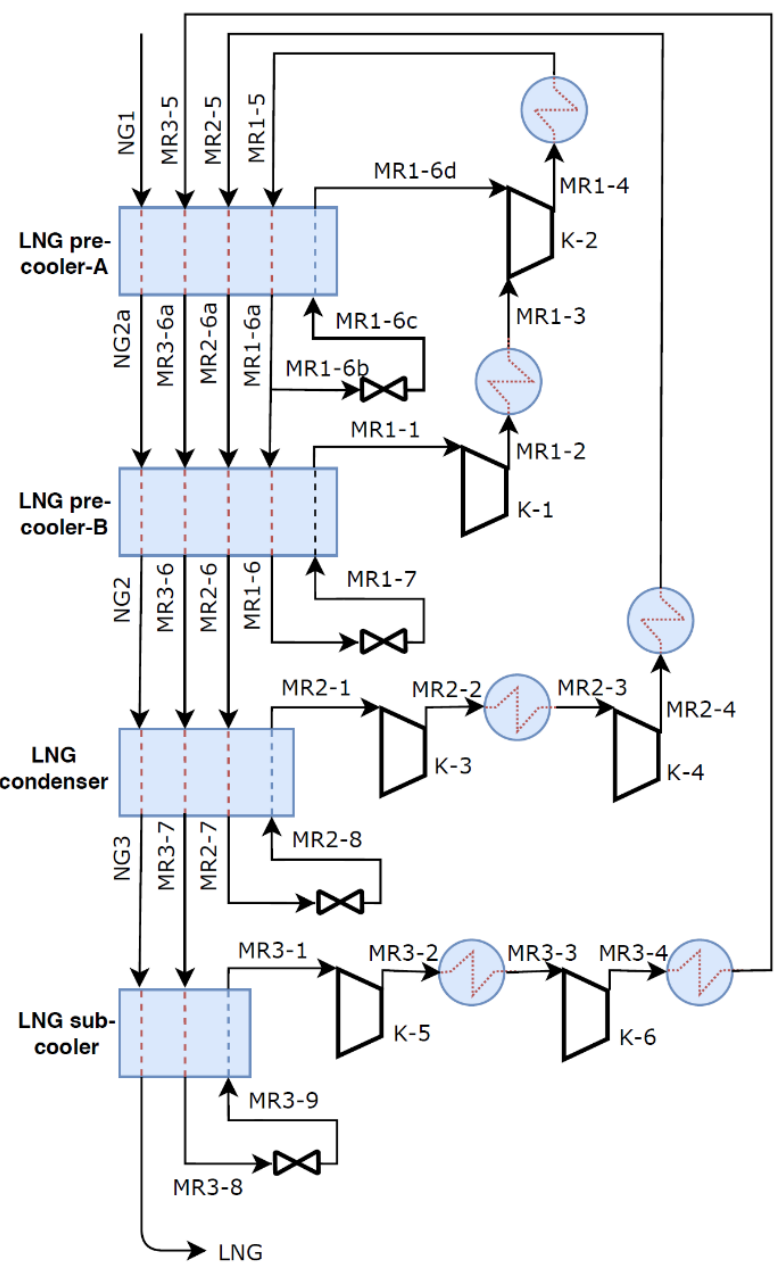

Case C (alterations to Case B).

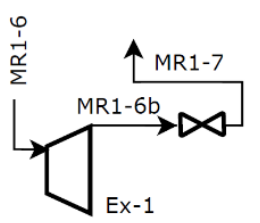

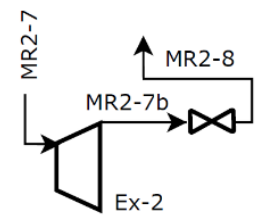

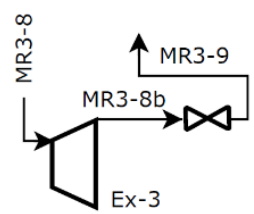

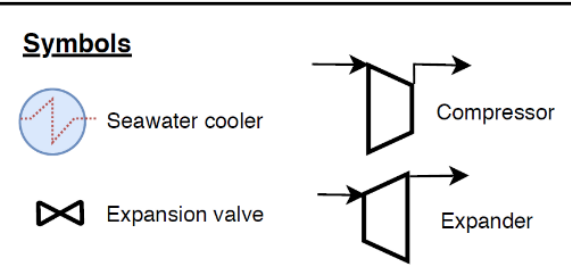

Figure 1. Flow diagrams illustrating the different MFC design for case $A, A^{*}, B$ and $C$. 


\subsection{System Performance}

For case $A, A^{*}$ and $B$ the specific energy consumption of the MFC process is defined as the total work from the six compressors $\left(\sum_{i=1}^{6} W_{\mathrm{K}-i}\right)$ per ton refrigerated natural gas $\left(m_{\mathrm{NG}}\right)$ :

$$
w_{\mathrm{MFC}}=\frac{\left(\sum_{i=1}^{6} W_{\mathrm{K}-i}\right)}{m_{\mathrm{NG}}} .
$$

The overall specific power consumption for case $C$, which also generates power in three expanders $\left(\sum_{i=1}^{3} W_{\mathrm{Ex}-i}\right)$, is defined as:

$$
w_{\mathrm{MFC}}=\frac{\left(\sum_{i=1}^{6} W_{\mathrm{K}-i}\right)-\left(\sum_{i=1}^{3} W_{\mathrm{Ex}-i}\right)}{m_{\mathrm{NG}}} .
$$

\subsubsection{Theoretical Minimum Power Consumption (Carnot Cascade)}

The Carnot process has the best refrigeration efficiency between two reservoirs. The most efficient process to cool the NG from $T_{\mathrm{NG} 1}$ to $T_{\mathrm{LNG}}$ is therefore to use an infinite number of Carnot stages. Numerically this is solved using a (large) finite number of cooling stages with temperature $T_{i}$ :

$$
w_{\mathrm{NG}}^{\text {Ideal }} \approx \sum_{i} \frac{T_{\mathrm{amb}}-T_{i}}{T_{i}} \frac{Q_{i}}{m_{\mathrm{NG}}},
$$

with specific refrigeration duty $Q_{i} / m_{\mathrm{NG}}=h_{\mathrm{NG}}\left(T_{i}\right)-h_{\mathrm{NG}}\left(T_{i+1}\right)$ defined from specific enthalpies of the natural gas $h_{\mathrm{NG}}$ during the cooling process, as explained in detail by Jackson et al. [4].

\subsection{Process Specifications}

The natural gas is assumed to have the specifications listed in Table 1. The energy consumption of the MFC process depends on the ambient seawater temperature $\left(T_{\mathrm{amb}}\right)$, which is here modelled over the range 0 to $40^{\circ} \mathrm{C}$ to cover a normal maximum operating range for LNG plants of 5 to $35^{\circ} \mathrm{C}$ [4]. Each of the three MR streams is defined to be a mixture of three components, as described in Table 2. The modeling assumptions implemented in the HYSYS model are described in Table 1-Table 3.

Table 4 explains additional constraints implemented trough the penalty function introduced in the MATLAB optimization algorithm, which are applied to make the behavior of the model as realistic as possible. The HYSYS parameters being optimized in MATLAB are shown in Table 5.

Table 2. Mixed refrigerant components.

\begin{tabular}{|l|l|l|}
\hline $\mathrm{MR} 1$ & $\mathrm{MR2}$ & $\mathrm{MR3}$ \\
\hline $\mathrm{i}-\mathrm{C}_{4} \mathrm{H}_{8}$ & $\mathrm{C}_{3} \mathrm{H}_{8}$ & $\mathrm{C}_{2} \mathrm{H}_{6}$ \\
$\mathrm{C}_{3} \mathrm{H}_{8}$ & $\mathrm{C}_{2} \mathrm{H}_{6}$ & $\mathrm{CH}_{4}$ \\
$\mathrm{C}_{2} \mathrm{H}_{6}$ & $\mathrm{CH}_{4}$ & $\mathrm{~N}_{2}$ \\
\hline
\end{tabular}

Table 3. Process specifications implemented as input parameters in the HYSYS model.

- All streams going through heat exchangers have a fixed pressure drop of $\Delta p=0.5$ bar

- All compressors and expanders have isentropic efficiency of $\eta=0.85$

- $\quad$ Refrigerants are at bubble point (vapor fraction $X=0$ ) at MR1-5, MR2-6 and MR3-7:

$X_{\text {MR1-5 }}=X_{\text {MR2-6 }}=X_{\text {MR3-7 }}=0$

- Temperatures of multiple streams being chilled in exchangers are identical:

$T_{\mathrm{MR} 1-6}=T_{\mathrm{MR3}-6}=T_{\mathrm{MR2}-6}=T_{\mathrm{NG2}}, T_{\mathrm{MR2}-7}=T_{\mathrm{MR} 3-7}=T_{\mathrm{NG} 3}$ and $T_{\mathrm{MR3}-8}=T_{\mathrm{LNG}}$

- Seawater coolers are removed if they are reducing the efficiency of the LNG production, otherwise, a $3 \mathrm{~K}$ temperature difference is assumed in seawater coolers:

$T_{\mathrm{NG1}}=T_{\mathrm{MR} 1-3}=T_{\mathrm{MR} 1-5}=T_{\mathrm{MR2}-3}=T_{\mathrm{MR2}-5}=T_{\mathrm{MR3}-3}=T_{\mathrm{MR} 3-5}=T_{\mathrm{amb}}+3 \mathrm{~K}$

- A $3 \mathrm{~K}$ temperature approach is assumed for the superheating:

$T_{\mathrm{MR} 1-1}=T_{\mathrm{NG} 1}-3 \mathrm{~K}, T_{\mathrm{MR2}-1}=T_{\mathrm{NG} 2}-3 \mathrm{~K}$, and $T_{\mathrm{MR} 3-1}=T_{\mathrm{NG} 3}-3 \mathrm{~K}$

0 Only case $A^{*}: 3 \mathrm{~K}$ temperature difference between the warm streams and the cold refrigerant: $\Delta T_{\mathrm{MR} 1-7}=T_{\mathrm{NG} 2}-T_{\mathrm{MR} 1-7}=3 \mathrm{~K}, \Delta T_{\mathrm{MR2}-8}=T_{\mathrm{NG} 3}-T_{\mathrm{MR2}-8}=3 \mathrm{~K}$ and $\Delta T_{\mathrm{MR} 3-9}=T_{\mathrm{LNG}}-T_{\mathrm{MR3}-9}=3 \mathrm{~K}$ 
Table 4. Process specifications (constraints) implemented through penalties in the optimization routine.

- Minimum allowed compressor pressure ratio is 2 :

$p_{\text {MR1-2 }} / p_{\text {MR1-1 }} \geq 2, p_{\text {MR1-4 }} / p_{\text {MR1-3 }} \geq 2, p_{\text {MR2-2 }} / p_{\text {MR2-1 }} \geq 2, p_{\text {MR2-4 }} / p_{\text {MR2-3 }} \geq 2, p_{\text {MR3-2 }} / p_{\text {MR3-1 }} \geq 2$ and $p_{\text {MR3-4 }} / p_{\text {MR3-3 }} \geq 2$

- Minimum allowed superheating before the compressors is $10 \mathrm{~K}$ :

$T_{\text {MR1-1 }} \geq T_{\text {dew }}+10 \mathrm{~K}, T_{\text {MR1-3 }} \geq T_{\text {dew }}+10 \mathrm{~K}, T_{\text {MR2-1 }} \geq T_{\text {dew }}+10 \mathrm{~K}, T_{\text {MR2-3 }} \geq T_{\text {dew }}+10 \mathrm{~K}$,

$T_{\text {MR3-1 }} \geq T_{\text {dew }}+10 \mathrm{~K}$ and $T_{\text {MR3-3 }} \geq T_{\text {dew }}+10 \mathrm{~K}$

- Minimum allowed pressure in the refrigeration cycles is $1.1 \mathrm{bar}:$

$p_{\text {MR1-1 }} \geq 1.1$ bar, $p_{\text {MR2-1 }} \geq 1.1$ bar and $p_{\text {MR3-1 }} \geq 1.1$ bar

- Minimum allowed temperature pinch in the heat exchangers is $3 \mathrm{~K}$ :

$\Delta T_{\text {pinch,LNG condenser }} \geq 3 \mathrm{~K}$ and $\Delta T_{\text {pinch,LNG sub-cooler }} \geq 3 \mathrm{~K}$

o Only case $\mathrm{A}$ and $\mathrm{A}^{*}: \Delta T_{\text {pinch,LNG pre-cooler }} \geq 3 \mathrm{~K}$

Only case B and C: $\Delta T_{\text {pinch,LNG pre-cooler-A }} \geq 3 \mathrm{~K}$ and $\Delta T_{\text {pinch,LNG pre-cooler-B }} \geq 3 \mathrm{~K}$

o Refrigerants are at bubble point or subcooled when exiting the liquid expanders:

Only case C: $X_{\text {MR1-6b }} \leq 0, X_{\text {MR2-7b }} \leq 0$ and $X_{\text {MR3-8b }} \leq 0$

Table 5. Optimized process variables.

\begin{tabular}{|c|c|c|c|c|}
\hline & Case A* & Case A & Case B & Case C \\
\hline 1 & $n_{\mathrm{MR} 1, \mathrm{i}-\mathrm{C} 4 \mathrm{H} 10}$ & $n_{\mathrm{MR} 1, \mathrm{i}-\mathrm{C} 4 \mathrm{H} 10}$ & $n_{\mathrm{MR} 1 \mathrm{i}-\mathrm{C} 4 \mathrm{H} 10}$ & $n_{\mathrm{MR} 1, \mathrm{i}-\mathrm{C} 4 \mathrm{H} 10}$ \\
\hline 2 & $n_{\mathrm{MR} 1, \mathrm{C} 3 \mathrm{H} 8}$ & $n_{\mathrm{MR} 1, \mathrm{C} 3 \mathrm{H} 8}$ & $n_{\mathrm{MR} 1, \mathrm{C} 3 \mathrm{H} 8}$ & $n_{\mathrm{MR} 1, \mathrm{C} 3 \mathrm{H} 8}$ \\
\hline 3 & $n_{\mathrm{MR} 2, \mathrm{C} 3 \mathrm{H} 8}$ & $n_{\mathrm{MR} 2, \mathrm{C} 3 \mathrm{H} 8}$ & $n_{\mathrm{MR2, \textrm {C }} \mathrm{H} 8}$ & $n_{\mathrm{MR} 2, \mathrm{C} 3 \mathrm{H} 8}$ \\
\hline 4 & $n_{\mathrm{MR} 2, \mathrm{C} 2 \mathrm{H} 4}$ & $n_{\mathrm{MR} 2, \mathrm{C} 2 \mathrm{H} 4}$ & $n_{\mathrm{MR} 2, \mathrm{C} 2 \mathrm{H} 4}$ & $n_{\mathrm{MR} 2, \mathrm{C} 2 \mathrm{H} 4}$ \\
\hline 5 & $n_{\mathrm{MR} 3, \mathrm{CH} 4}$ & $n_{\mathrm{MR} 3, \mathrm{CH} 4}$ & $n_{\mathrm{MR} 3, \mathrm{CH} 4}$ & $n_{\mathrm{MR} 3, \mathrm{CH} 4}$ \\
\hline 6 & $n_{\mathrm{MR} 3, \mathrm{~N} 2}$ & $n_{\mathrm{MR} 3, \mathrm{~N} 2}$ & $n_{\mathrm{MR} 3, \mathrm{~N} 2}$ & $n_{\mathrm{MR} 3, \mathrm{~N} 2}$ \\
\hline 7 & $p_{\text {MR1-2 }}$ & $p_{\text {MR1-2 }}$ & $p_{\text {MR1-2 }}$ & $p_{\mathrm{MR} 1-2}$ \\
\hline 8 & $p_{\text {MR2-2 }}$ & $p_{\text {MR2-2 }}$ & $p_{\text {MR2-2 }}$ & $p_{\text {MR2-2 }}$ \\
\hline 9 & $p_{\text {MR3-2 }}$ & $p_{\text {MR3-2 }}$ & $p_{\text {MR3-2 }}$ & $p_{\text {MR3-2 }}$ \\
\hline 10 & $T_{\mathrm{NG} 2}$ & $T_{\mathrm{NG} 2}$ & $T_{\mathrm{NG2}}$ & $T_{\mathrm{NG} 2}$ \\
\hline 11 & $T_{\mathrm{NG} 3}$ & $T_{\mathrm{NG3}}$ & $T_{\mathrm{NG3}}$ & $T_{\mathrm{NG3}}$ \\
\hline 12 & & $\Delta T_{\text {MR1-7 }}$ & $\Delta T_{\text {MR1-7 }}$ & $\Delta T_{\text {MR1-7 }}$ \\
\hline 13 & & $\Delta T_{\text {MR2-8 }}$ & $\Delta T_{\text {MR2-8 }}$ & $\Delta T_{\text {MR2-8 }}$ \\
\hline 14 & & $\Delta T_{\text {MR3-9 }}$ & $\Delta T_{\text {MR3-9 }}$ & $\Delta T_{\text {MR3-9 }}$ \\
\hline 15 & & & $\Delta T_{\mathrm{NG} 2 \mathrm{a}}$ & $\Delta T_{\mathrm{NG} 2 \mathrm{a}}$ \\
\hline 16 & & & & $p_{\text {MR1-6b }}$ \\
\hline 17 & & & & $p_{\text {MR2-7b }}$ \\
\hline 18 & & & & $p_{\text {MR3-8b }}$ \\
\hline
\end{tabular}

2.4. Optimal System Design and Multivariable Optimization

The MFC performance is optimized in MATLAB using Actxserver to pass data to the process models implemented in HYSYS, which then calculates the specific energy consumption $w_{\mathrm{MFC}}$, the values related to the constraints listed in Table 4, and the UA value for each LNG heat exchanger.

\subsubsection{Pinch Based Optimization}

The objective function in the minimization problem is defined as:

$$
\min \left\{w_{\mathrm{MFC}}\right\},
$$

for case A, A*, B and C. The parameters being optimized are listed in Table 5. The constraints listed in Table 4 are implemented through a penalty function $q$, which is minimized using standard optimization algorithms:

$$
q=w_{\mathrm{MFC}}+\sum_{i=1}^{n} k_{i} \cdot\left[\max \left(0, g_{i}\right)\right]^{2},
$$

where $k_{i}$ are penalty factors and $g_{i}$ constraints function listed in Table 4. For example, the constraint function for the pinch constraint in the LNG condenser is:

$$
g_{1}=3 \mathrm{~K}-\Delta T_{\text {pinch, LNG condenser. }}
$$


Optimization methods are often divided into two groups: deterministic and stochastic based algorithms, and most LNG articles use deterministic methods [23]. To obtain an accurate result, the present work uses a large sequence of deterministic fminsearch and stochastic particle swarm evaluations for each optimization problem, using algorithms from the MATLAB optimization toolbox. Fminsearch is based on the Nelder-Mead simplex algorithm [24], while particle swarm is based on the algorithm described by Kennedy and Eberhart [25]. The particle swarm has earlier been applied to similar problems, e.g. by Khan and Lee to optimize the SMR process [20].

\subsubsection{UA Value Based Post Modeling}

The optimized variables based on a minimum allowed temperature pinch can be used as a first approach when designing an LNG plant. The results can, for example, be used to calculate UA values of the individual heat exchangers, and the combined UA value of the LNG pre-cooler, condenser, and sub-cooler can then be used to compare and optimize MFC systems with a fixed UA value.

The main goal in this article is to study the benefit realizable through different modifications and to

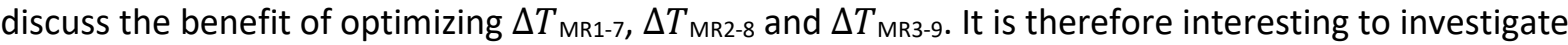
if the improved performance corresponds to a better process design, i.e. smaller combined $U A$ values. This is done by reoptimizing the three parameters $\Delta T_{\text {MR1-7 }}, \Delta T_{\text {MR2-8 }}$ and $\Delta T_{\text {MR3-9 }}$ with new optimization criteria, while the other optimized variables in Table 5 are kept constant. This problem is optimized directly by defining discrete variables $\Delta T_{\text {MR1-7, }} \Delta T_{\text {MR2-8 }}$ and $\Delta T_{\text {MR3-9 }}$ on a three dimensional grid, and evaluating the performance parameter $w_{\mathrm{MFC}}$, the $U A$ value and the constraint violations $g_{i}$ at each point. Six new modified cases are studied to compare case $A$ with case $A^{*}$, case $B$ with case $A$ and case $C$ with case $B$ :

Case $A_{1}: \min \left\{w_{\mathrm{MFC}}\right\}, \quad$ with $U A$ less or equal the value from case $A^{*}$ Case $A_{2}: \min \{U A\}, \quad$ with $w_{\mathrm{MFC}}$ less or equal the value from case $A^{*}$

Case $B_{1}: \min \left\{w_{\mathrm{MFC}}\right\}$, with $\cup A$ less or equal the value from case $A$

Case $\mathrm{B}_{2}: \min \{U A\}, \quad$ with $w_{\mathrm{MFC}}$ less or equal the value from case $\mathrm{A}$

Case $C_{1}: \min \left\{w_{\mathrm{MFC}}\right\}$, with $\cup A$ less or equal the value from case $B$

Case $C_{2}: \min \{U A\}, \quad$ with $w_{\mathrm{MFC}}$ less or equal the value from case $\mathrm{B}$

That is, case $A_{1}$ has a $U A$ value less or equal to case $A^{*}$, and the same optimized parameters as case A, except that $\Delta T_{\text {MR1-7 }}, \Delta T_{\text {MR2-8 }}$ and $\Delta T_{\text {MR3-9 }}$ are changed in order to minimize the energy consumption. Case $A_{2}$ is the opposite situation, i.e. minimizing $U A$ while requiring that the energy usage is less or equal to the value from case $A^{*}$. Only cases which do not violate the constraints in Table 4 are accepted.

\section{Results}

Optimized performance parameters based on minimum allowed temperature pinch for case $A^{*}, A, B$ and $\mathrm{C}$ are presented in the first section. The second section shows how the optimized models compare with respect to $U A$ values for small design variations in $\Delta T_{\text {MR1-7, }} \Delta T_{\text {MR2-8 }}$ and $\Delta T_{\text {MR3-9. }}$

\subsection{Optimization of Energy Usage}

The specific energy consumption for case $A^{*}, A, B$ and $C$ is plotted in Figure 2, together with the theoretical best Carnot process. Figure 2 also presents a consistency analysis, which contains information which can be related to the accuracy of the optimization.

Important process parameters from the optimized cases are illustrated in Figures $3-6$. Figure 3 and Figure 4 show, respectively, the optimized temperatures related to the main LNG heat exchanger and the three optimized mixed refrigerants at different ambient temperatures. Figure 5 shows that the 
pressure ratio, minimum pressure, and superheating constraints from Table 4 are fulfilled. The overall reduction in specific work gained by adding liquid expanders, as well as the specific energy produced by each of the expanders in case $C$, are illustrated in Figure 6.

Figure 7 shows the temperature approach inside the LNG pre-cooler, condenser, and sub-cooler. All of the optimized results presented in this study meet the temperature pinch constraints with a tolerance of $0.01{ }^{\circ} \mathrm{C}$. The average temperature difference for the heat being transferred in the LNG exchangers is given in Figure 8, which also shows the temperature differences in greater detail as well as the accumulated $U A$ values calculated by HYSYS. Note that specific UA values are used since the heat transfer is proportional to the natural gas mass flow $\dot{m}_{\mathrm{NG}}$.

In case $C$, it is required that the expanders only operate with refrigerants in the liquid phase. The optimization MATLAB code for case $C$ was also rewritten slightly to model multiphase expanders by removing the bubble point constraints listed in Table 4 . This modification was only modelled for $0{ }^{\circ} \mathrm{C}$ ambient temperature, and the optimized case used $155.9 \mathrm{kWh} /$ (ton NG), which is only slightly better than the $156.5 \mathrm{kWh} /$ (ton NG) used by case C. Due to the small gain, less than $0.4 \%$, multiphase expanders were not modelled for other temperatures.
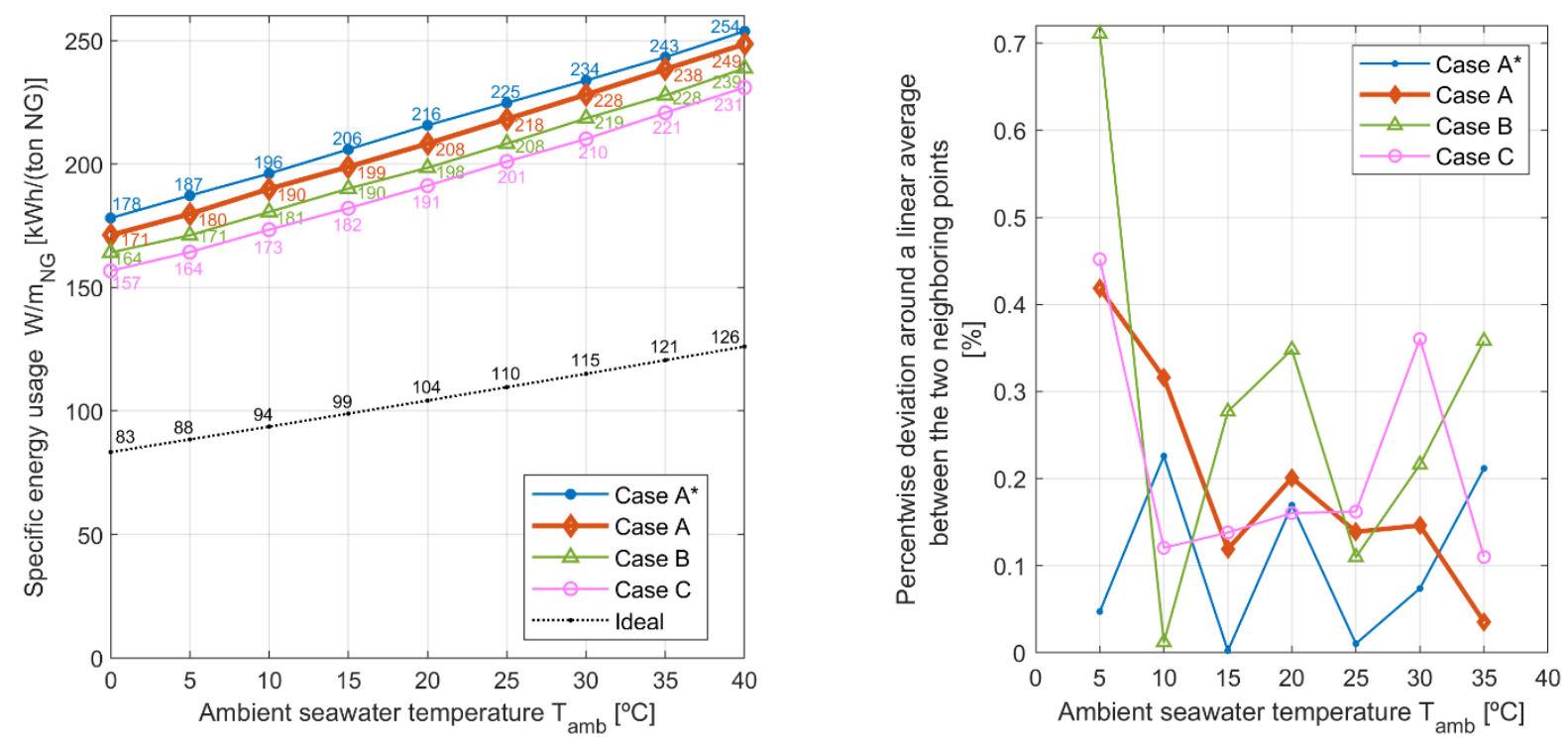

Figure 2. Left: Specific energy usage (optimized). The ideal performance is modelled using Eq. (4). Right: Smoothness estimate for the curves presented in the left figure based on a moving linear average.
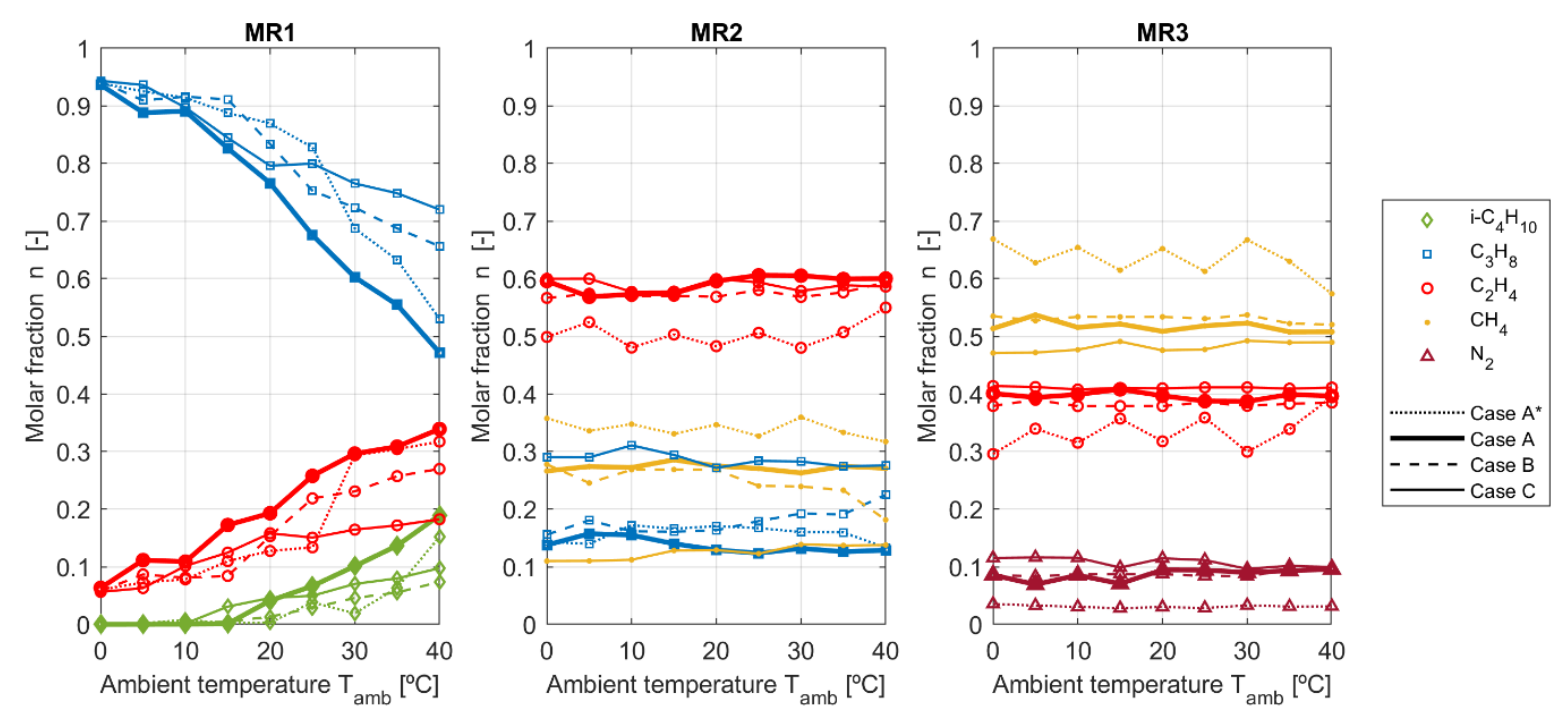
Figure 3. Optimized refrigerants for the LNG pre-cooler (left), sub-cooler (middle) and condenser (right) cycles.

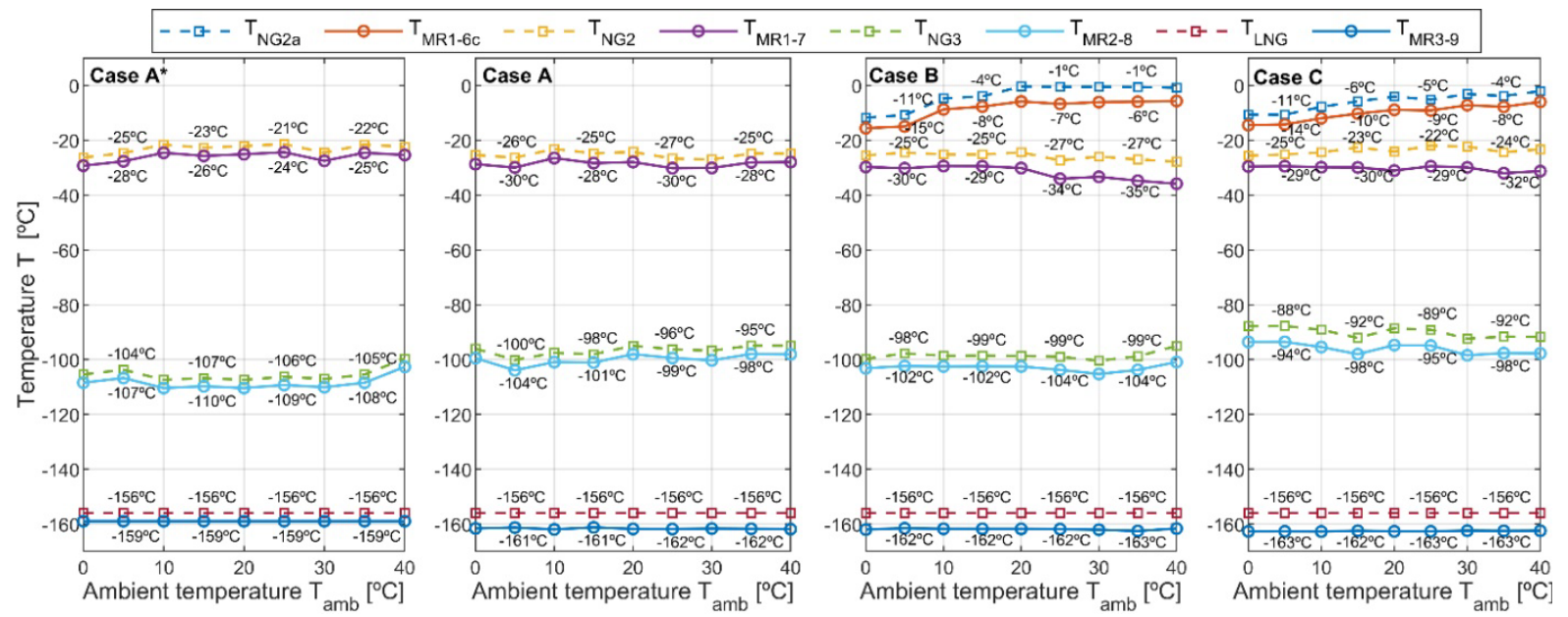

Figure 4. Optimized temperatures. Note that $\Delta T_{M R 1-7,} \Delta T_{M R 2-8,} \Delta T_{M R 3-9,}$ and $\Delta T_{N G 2 a}=T_{N G 2 a}-T_{M R 1-6 c}$ in case $A, B$ and $\mathrm{C}$ often are larger than the $3 \mathrm{~K}$ pinch constraint.
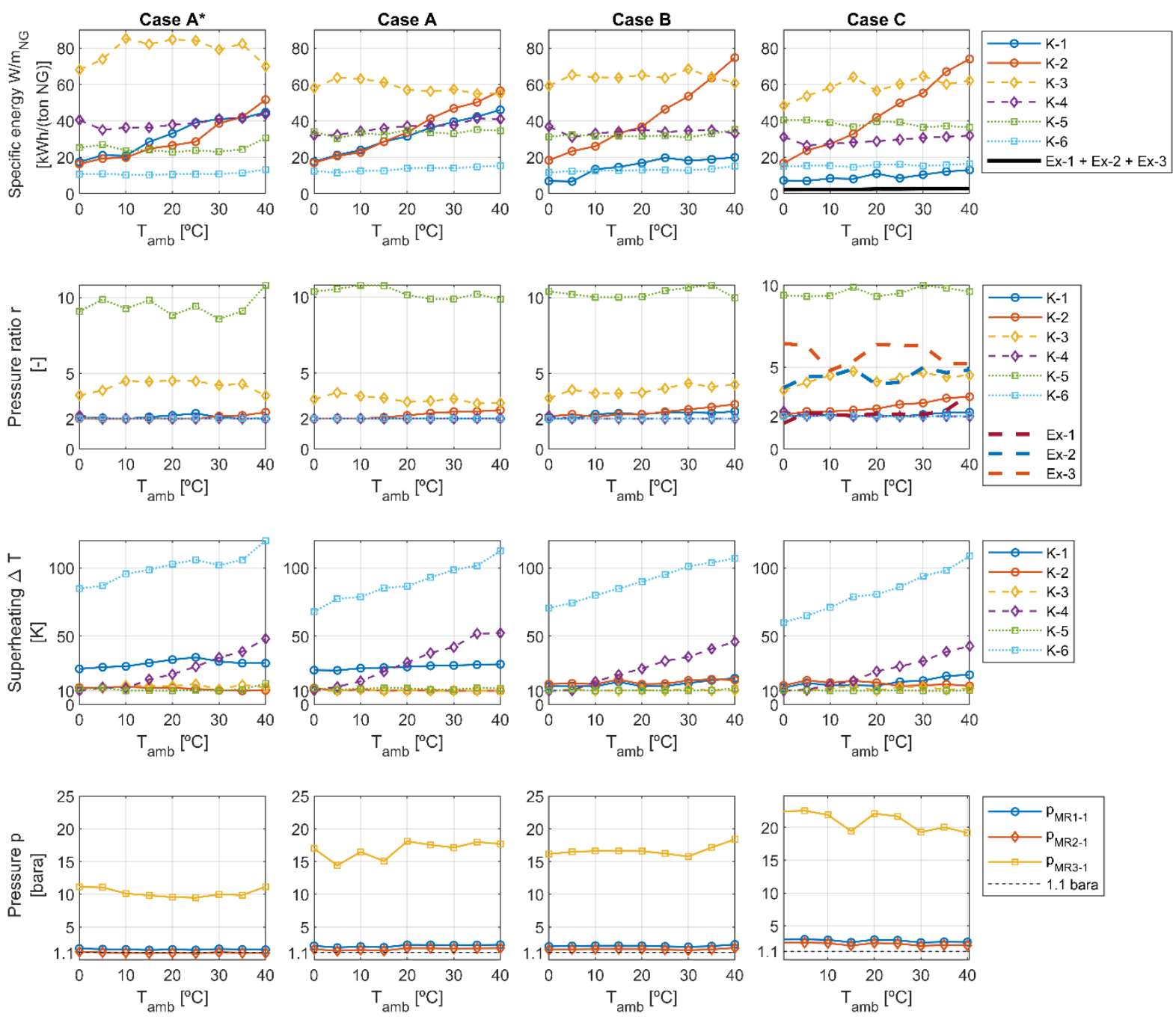

Figure 5. Important process parameters in optimized systems for different ambient temperatures $T_{\text {amb. }}$. 


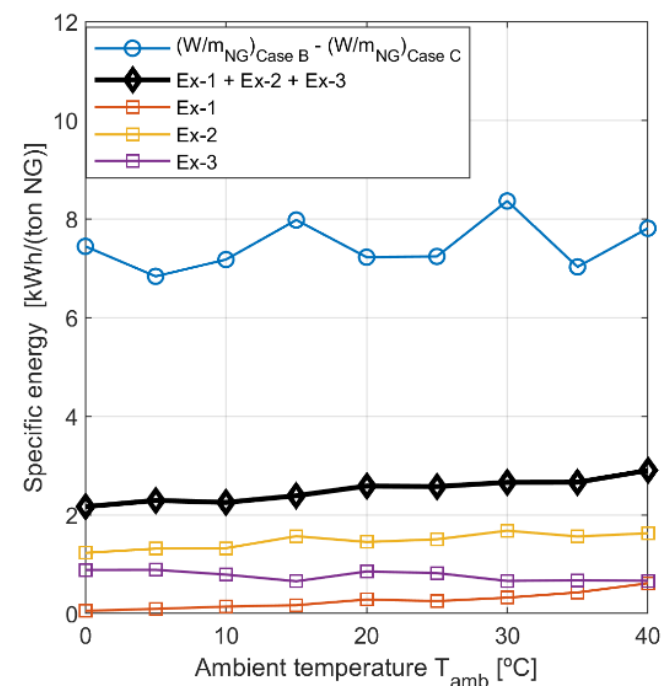

Figure 6. Energy recovered by the three liquid expanders (Ex-1, Ex-2 and Ex-3) in case $C$, and the improvements they provide to the overall MFC energy consumption, i.e. the difference between case $B$ and $C$.
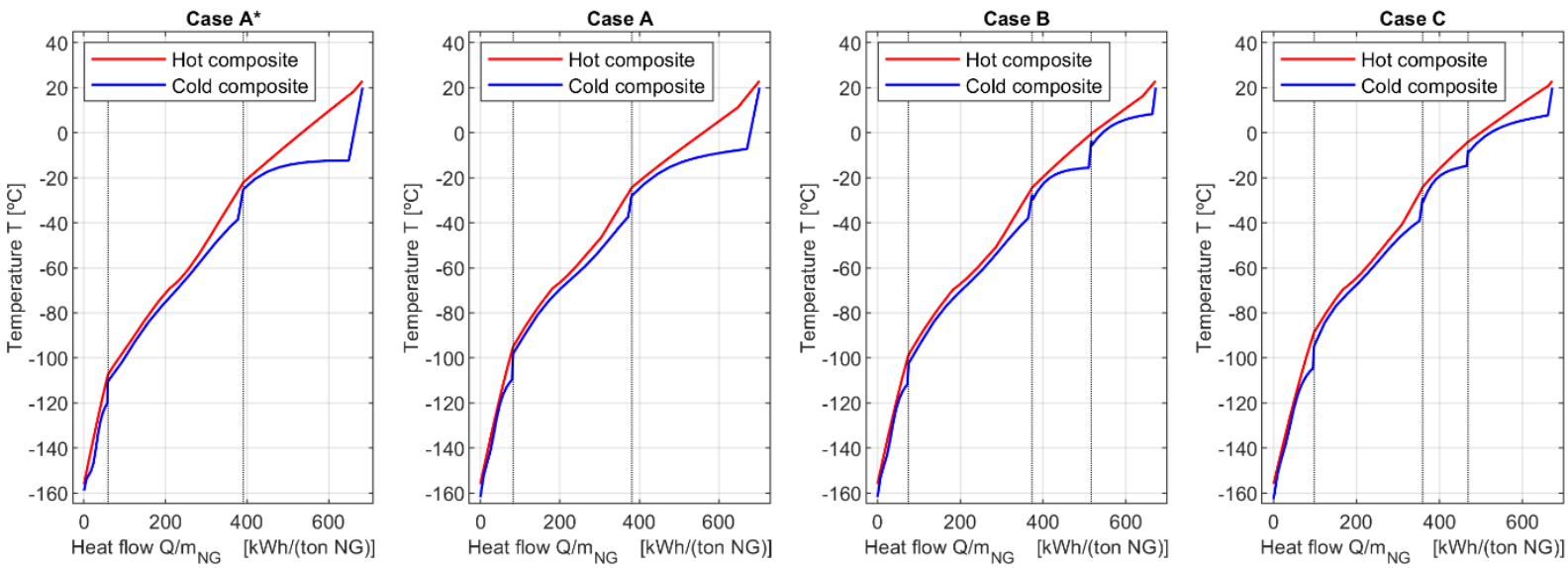

Figure 7. Temperature profiles in the $L N G$ sub-cooler, condenser and pre-cooler for $T_{a m b}=20^{\circ} \mathrm{C}$ (Case $B$ and $C$ have two pre-coolers). 

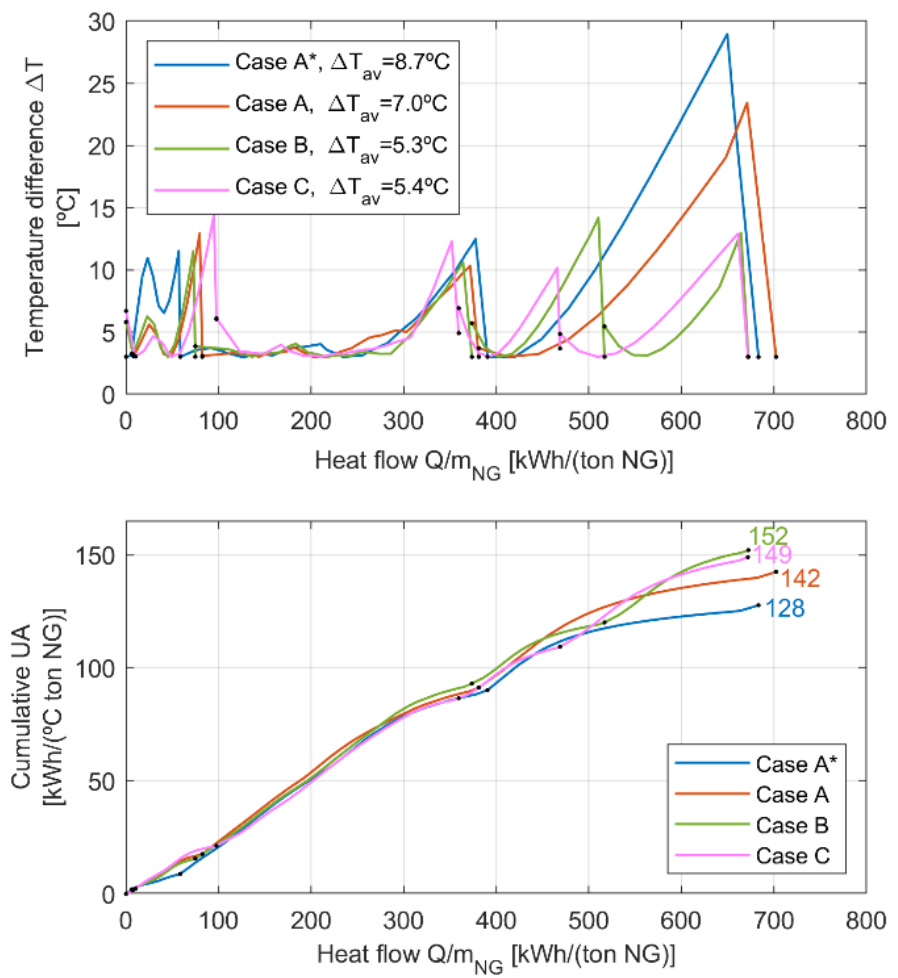

Figure 8. Top: Temperature approach inside the LNG sub-cooler, condenser and pre-cooler(s) at $T_{a m b}=20^{\circ} \mathrm{C}$, and includes the average temperature difference ( $\Delta T$ av) for the heat exchange. Bottom: Cumulative $U A$ values.

\subsection{UA Value versus Energy Consumption}

Figure 8 shows that case $A^{*}, A, B$ and $C$ have different $U A$ values. Figure 2 shows that the energy consumption is improved if case $A$ is modified with a two-stage pre-cooler modification represented by case $B$, but the overall $U A$ value is also increased (see Figure 8 ). The results in this section show variations in $U A$ and energy consumption for the six new cases described in Eqs. (8) - (13): $A_{1}, A_{2}, B_{1}$, $B_{2}, C_{1}$ and $C_{2}$. These cases are comparing case $A$ with case $A^{*}$, case $B$ with case $A$ and case $C$ with case $B$. For example, Case $B_{1}$ has a $\cup A$ value less or equal to case $A$, and the same optimized parameters as case $\mathrm{B}$, except that $\Delta T_{\mathrm{MR1-7},}, \Delta T_{\mathrm{MR2}-8,}, \Delta T_{\mathrm{MR3}-9}$ and $\Delta T_{\mathrm{NG2}}$ are changed in order to minimize the energy consumption. Case $B_{2}$ is the opposite situation, i.e. minimizing $U A$ while requiring that the energy usage is less or equal the value from case $A$.

The performance and corresponding UA values calculated by HYSYS are presented in Figure 9, which also shows the percent improvement for each modification. Figure 10 presents the best design

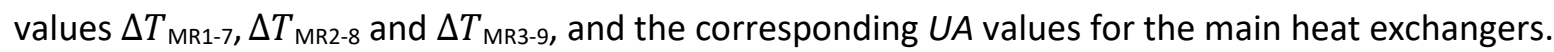



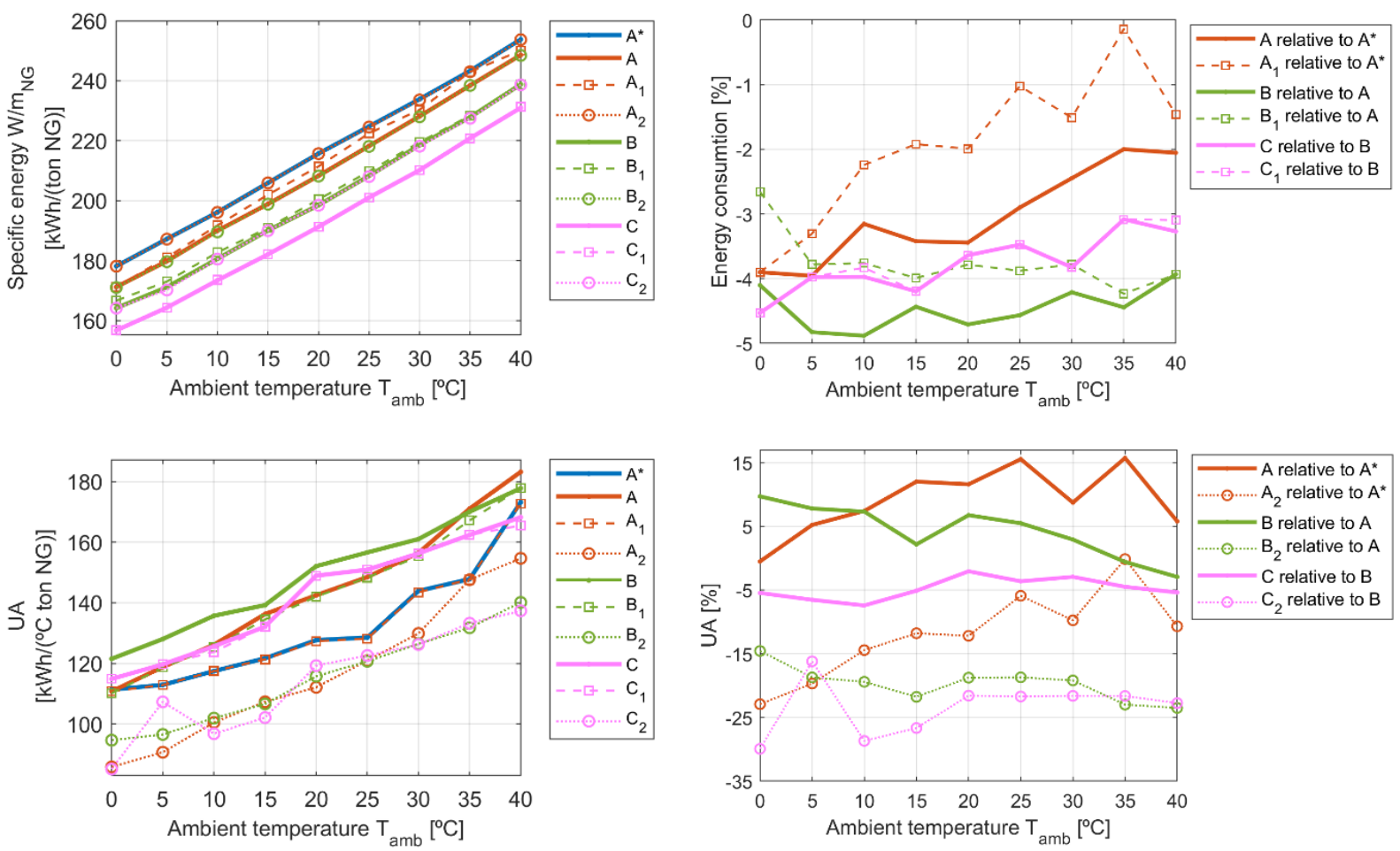

Figure 9. Specific energy consumption $W_{M F C}$ and the corresponding UA value for all cases considered in this article (left), and corresponding differences in percentage (right).
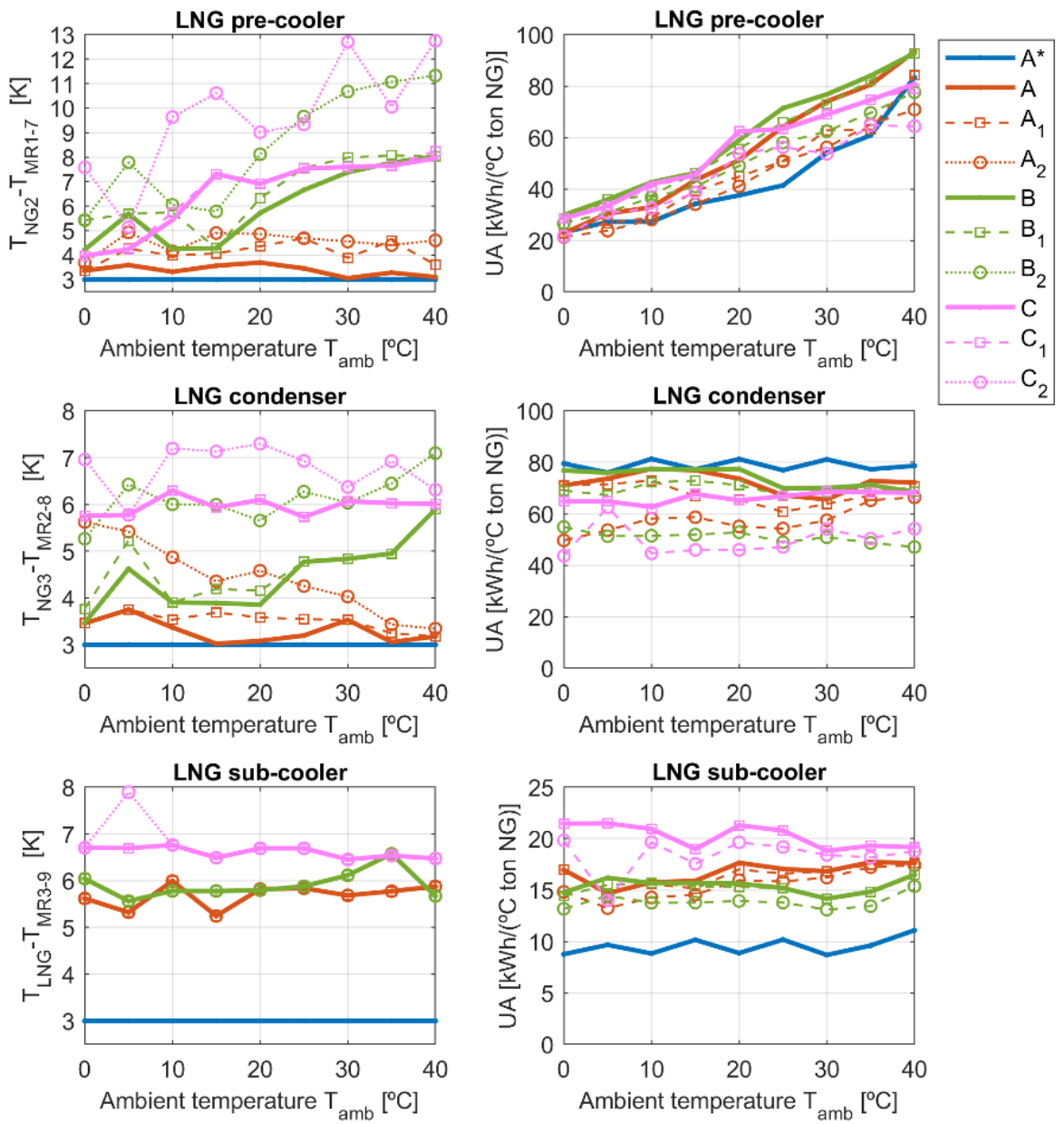

Figure 10. Best design $\Delta T_{M R 1-7,} \Delta T_{M R 2-8}$ and $\Delta T_{M R 3-9}$ values, and the corresponding $U A$ value in the different $L N G$ Exchangers. In $B$ and $C$ cases, the combined UA value of the two LNG pre-coolers is shown. 


\section{Discussion}

This chapter discusses the optimized MFC performance results, and how the performance is affected by ambient temperature, different process modifications and simplifications in the modelling work regarding temperature pinch implementations.

\subsection{Optimization Method and Consistency}

All the optimization algorithms used in this work are forced to search for a solution that do not violate the constraints using a penalty function. When such a solution is found, it is often impossible for the algorithm to continue optimizing by changing only one optimization parameter, such as temperature $T_{\mathrm{NG} 3}$ or $T_{\mathrm{NG} 3}$, or a component mole fraction, without violating the constraints. This is a well known problem. Ding et al. [7], for example, overcome this using a simplified optimization procedure where each refrigeration cycle was optimized individually in a sequence from the subcooling cycle to the pre-cooling cycle. In this study, a large sequence of the optimization algorithms 'fminsearch' and 'particle swarm' were used in order to obtain an accurate result, where fminsearch often was found to improve the optimization by exploring a smaller region around the optimized particle swarm solution.

The temperature approach in the heat exchangers is related to entropy generation and thermodynamical loss, and Figure 7 and Figure 8 show that the optimized parameters correspond to an energy efficient system due to the tight temperature approaches in all the main heat exchangers. Figure 8, for example, shows that in Case $A^{*}, A, B$ and $C$ heat is transferred at an average temperature difference of only $8.7^{\circ} \mathrm{C}, 7.7^{\circ} \mathrm{C}, 5.3^{\circ} \mathrm{C}$ and $5.4^{\circ} \mathrm{C}$, respectively. That is, the average temperature approach in the $L N G$ heat exchangers in case $B$ is only $2.3 \mathrm{C}$ above the minimum allowed pinch used in the simulations.

Previous papers have typically only presented figures showing a tight temperature approach to prove that the optimization was successful $[8,17,19,20]$. However, the sensitivity study presented here contains more information since it optimizes nine different ambient temperatures for each design, which can be compared and used to strengthen the argument that the optimization was successful. For example, the optimized energy usage in Figure 2 shows a relatively smooth behavior with typically less than $0.5 \%$ deviation around a linear average between the two neighboring points. Figure 2 shows that the largest deviation was approximately $0.7 \%$ for the case $B$ design at $0{ }^{\circ} \mathrm{C}$ ambient temperatures. However, this point was continuously optimized over almost a week without improving, and it is possible that the deviation from a linear behavior in this case also had a physical explanation, e.g. related to the constraints.

The accuracy of the optimization algorithm is not perfect, as illustrated by the random oscillations from point to point in Figures $3-5$. However, the smoothness of the objective function indicates a relatively large parameter span of different input combinations which are almost equally efficient. This has not been discussed extensively in the literature, since previous work has typically only studied single cases. The only sensitivity study based on mathematical optimization algorithms is presented by Ding et al. [7], but this work does not discuss fluctuations in the parameters being optimized since they assumed constant values for the NG temperature between the LNG heat exchangers and did not present data showing the optimum refrigerant compositions at different ambient temperatures.

Figure 3 shows that there are relatively large oscillations in the composition of the optimized refrigerant mixtures MR2 and MR3 for case A. These oscillations are mirrored to the smoothness estimate shown in Figure 2, which shows that the deviation around a moving linear average is less than $0.2 \%$. The significant range of parameters that result in almost identical energy consumptions 
indicate a wide minimum and that the system is optimized with more freedom than strictly necessary. The temperature fluctuations seen in Figure 4 also indicate that it is possible to create a relatively accurate model using a simplified approach which does not optimize $T_{\mathrm{NG2}}$ and $T_{\mathrm{NG} 3}$ for each ambient temperature level, once a set of optimal parameters is found for one characteristic ambient temperature level. This aproach was applied by Ding et al. [7], but it is unclear if the constant values they assumed for $T_{\mathrm{NG2}}$ and $T_{\mathrm{NG} 3}$ were found through optimization or not.

Other articles that directly optimize the temperature differences ( $\Delta T_{\text {MR1-7 }}, \Delta T_{\text {MR2-8 }}, \Delta T_{\text {MR3-9 }}$ and $\Delta T_{\mathrm{NG2}}$ ) at the end of the exchangers in MFC processes were not identified, but the results in this article show that this approach can be used. Even though, the search interval of the optimized temperature differences are small, between $3^{\circ} \mathrm{C}$ and $8{ }^{\circ} \mathrm{C}$ as illustrated in Figure 4 , it was difficult for the optimization algorithms to solve the penalty problem. However, since the previously applied methods were not tested, it is unclear if this approach is better.

Figures $2-8$ are based on optimization of continuous variables using the optimization algorithms 'fminsearch' and 'particle swarm'. The optimized cases are then used to compare systems based on the $U A$ value using a simplified optimization scheme that only optimizes $\Delta T_{\text {MR1-7, }}, \Delta T_{\text {MR2-8 }}$ and $\Delta T_{\text {MR3-9 }}$ as discrete variables using Eqs. (8) - (13). The results presented in Figure 9 and Figure 10 show information of the larger trends, but also contain oscillations since they are based on optimized variables that also oscillates such as the mixed refrigerant composition shown in Figure 3 . These parameters were optimized with respect to energy usage and Figure 9 and Figure 10 shows that the deviation from a linear behavior is much larger than for the specific energy consumption.

\subsection{Impact of Ambient Temperature}

The ambient temperature is important for the LNG production energy efficiency. If ambient temperature is increased from $5{ }^{\circ} \mathrm{C}$ to $35^{\circ} \mathrm{C}$, Figure 2 shows that the energy consumption of case $\mathrm{A}, \mathrm{B}$ and $\mathrm{C}$ processes increases with $32 \%, 33 \%$ and $35 \%$, respectively. An ideal process based on infinite Carnot cycles increases with $38 \%$. The results presented in Figure 2 also compare well with the $13 \%$ reduction in energy consumption reported by Ding et al. [7] when the ambient temperature increases from $27^{\circ} \mathrm{C}$ to $39^{\circ} \mathrm{C}$.

The UA value of the LNG pre-cooler(s) heat exchangers depends strongly on ambient temperature. Figure 10 shows that $U A$ increases about $150 \%$ when the temperature is raised from $5{ }^{\circ} \mathrm{C}$ to $35^{\circ} \mathrm{C}$. The combined UA value of all the LNG heat exchangers increases with approximately $35 \%$.

Figure 3 shows that the optimal composition of the mixed refrigerant in the LNG pre-cooler circuit (MR1) depends strongly on ambient temperature, i.e. at $5{ }^{\circ} \mathrm{C}$ the best refrigerant is a mixture of approximately $89-94 \mathrm{~mol} \%$ propane and $6-11 \mathrm{~mol} \%$ ethane. At $35^{\circ} \mathrm{C}$ the best MR1 consist of $56-$ $75 \mathrm{~mol} \%$ propane, $17-31 \mathrm{~mol} \%$ ethane and $5-15 \mathrm{~mol} \% \mathrm{i}$-butane.

\subsection{Process Improvements}

Even though the MFC is recognized as one of the most efficient LNG processes, the energy consumption of the standard case (A) process can theoretically be reduced with approximately $50 \%$, as illustrated in Figure 2. Improvements due to the process modifications shown in Figure 1 are discussed below.

\subsubsection{Two-Stage versus One-Stage Pre-Cooler Cycles}

For all realistic ambient seawater temperatures, Figure 9 shows that that a $4.0 \%-5.0 \%$ reduction in power consumption is realizable by upgrading the one-stage pre-cooler cycle standard case with a two-stage pre-cooler cycle (case B). This is larger than the $3.38 \%$ reported by Ding et al. [7], who also reported an additional gain of $0.82 \%$ when upgraded from a two-stage to a three-stage pre-cooler 
cycle. Note that processes with case $B$ typically have larger $U A$ value than the case $A$ processes, however, case $B$ processes can be slightly modified with equal $U A$ value as case $A$ (case $B_{1}$ ), and still obtain $3 \%-4 \%$ reduction in energy usage.

Figure 9 also shows that a two-stage pre-cooler cycle (case $B_{2}$ ) can obtain the same efficiency as the base case using LNG heat exchangers with an overall UA value reduction between $15 \%-25 \%$. The percentage reduction strongly depends on the size of the minimum temperature pinch applied in the optimization work, i.e. this two-stage gain increase if the pinch is less than the $3 \mathrm{~K}$ used in this article.

\subsubsection{Liquid Expanders versus JT Valves}

Expanders are considered as a replacement for conventional JT valves when reducing the natural gas pressure to atmospheric, but they can also be used in the refrigerant cycles as illustrated in Figure 1 [8]. Figure 5 shows the optimized pressure ratios for the expanders and the compressors in the refrigerant cycles.

Figure 6 shows that the expander in the LNG condenser circuit (Ex-2) generates the most energy, while the contribution from expander Ex-1 in the pre-cooler circuit is close to zero at low ambient temperatures. Figure 6 also shows that although the overall energy recovered by the three expanders together lies between 2.0 and $3.0 \mathrm{kWh} /$ (ton NG), the overall energy reduction resulting from the implementation of the expanders in the MFC process is larger, around $7.5 \mathrm{kWh} /$ (ton NG). That is, most of the expander gain is not the direct energy production by the expanders, but gained due to the reduced thermodynamically losses in the refrigerant circuits.

Figure 9 illustrates that the overall gain of including liquid expanders in each cascade cycle, i.e. upgrading from case $B$ to case $C$, is a reduction in power consumption between $3.0 \%-4.5 \%$. The benefit of liquid expanders in the refrigerant cycles have earlier been discussed for SMR processes, where much larger savings, up to $16.5 \%$, have been reported [8].

The results presented here require that the expanders only operate with refrigerants in liquid phase, but also multiphase expanders can be used. For a $0{ }^{\circ} \mathrm{C}$ ambient temperature, a $0.38 \%$ reduction in the energy consumption was observed when allowing expanders to operate with non-zero gas fractions. As mentioned in the result chapter, multiphase expanders were not further investigated due to the small gain.

Figure 9 shows that although case $C$ have around $5 \%$ smaller $U A$ value than case $B$, case $C$ processes can be slightly modified (case $C_{1}$ ) to have an equal $U A$ value to case $B$, and still obtain $3 \%-4 \%$ reduction in energy usage. In addition, Figure 9 also shows that a cycle with liquid expanders can be modified (case $\mathrm{C}_{2}$ ) to obtain the same efficiency as one without (case $B$ ) with an overall $U A$ value reduction between $15 \%-30 \%$.

\subsubsection{Real MFC Processes versus Ideal}

Figure 2 shows that case A, B and C use $100 \%, 90 \%$ and $84 \%$ more energy than the theoretical best process at $20^{\circ} \mathrm{C}$ ambient temperature, respectively. The temperature profiles in the LNG exchangers show that the thermodynamically losses in the exchangers, due to temperature differences, are small in MFC processes with a two-stage pre-cooler cycle. There is not much more to gain by adding more pre-cooler stages, as discussed by Ding et al. [7]. The expanders in case $\mathrm{C}$ also reduce thermodynamic losses in the expansion valves, but there are still significant losses related to the compression stages. To further reduce the performance gap between the MFC process and the ideal process, compressor (and expander) efficiencies would need to be increased from the $85 \%$ isentropic efficiency used in this study. 


\subsection{Importance of Internal Pinches}

Creating an accurate optimization scheme for a MFC process is a relatively time-consuming task, which is probably outside a typical process engineers' field of knowledge. Results from simplified models based on manually optimized processes directly in graphical simulation software like HYSYS have been published [4, 22]. A common assumption in this type of optimization study is that the minimum temperature approach is located at the natural gas outlet of the LNG exchangers (as in case $\left.A^{*}\right)$. However, the more general case where the minimum approach temperature can lie at any point within each of the exchangers is assumed in Case A, B and C.

Much of the mixed refrigerant-based LNG literature present optimized results showing where the temperature pinches are located in the heat exchangers, such as Figure 7 and Figure 8. Some articles are reporting temperature pinches at the natural gas streams outlets of the heat exchangers $[7,20$, 21], while others do not $[8,9,19]$. Figure 2, Figure 8 and Figure 9 illustrates that designing a MFC process with an external heat exchanger pinch, as in case $A^{*}$, is not an optimal configuration. Figure 8 also shows that the average temperature difference for the overall heat exchange is almost $2{ }^{\circ} \mathrm{C}$ larger for case $A^{*}$ than the standard case A. By defining the pinch at the end of the exchangers the temperature approach has to increase further into the exchangers, as illustrated in Figure 7 and Figure 8. That is, all MR concentrations that generate purely internal pinches, as in Case A, B and C, are excluded in the optimization search space for case $A^{*}$. Figure 9 shows that the reduction in the MFC power consumption is between $2.0 \%-4.0 \%$, which is similar in size to the MFC improvements discussed above.

\section{Conclusion}

This paper presents a detailed sensitivity study of MFC system performance with regard to ambient seawater temperature, MR concentrations, exchanger pinch temperatures, the use of liquid expanders and exchanger UA. Important (optimized) process parameters are presented, such as the optimal MR concentrations. As discussed, the tight temperature approach in the heat exchangers and the smoothness of the energy consumption curves are believed to justify a sufficient optimization accuracy from an engineering perspective.

The results state the importance of the ambient temperature. For example, an MFC process in localization with a $35{ }^{\circ} \mathrm{C}$ ambient seawater temperature consumes $32 \%-35 \%$ more energy compared to one in a cold location with $5{ }^{\circ} \mathrm{C}$ ambient seawater temperature. In addition to the increased energy consumption, the LNG heat exchangers need an approximately $35 \%$ larger combined $U A$ value.

The reduction in power consumption realizable by upgrading a one-stage pre-cooler cycle (case A) to a two-stage pre-cooler cycle (case B) and including liquid expanders in each refrigerant cycle (case C) are similar. For all realistic ambient seawater temperatures both modifications give between $3.0 \%-$ $5.0 \%$ power reductions. The improved performance due to each modification can also be translated into a $15 \%-30 \%$ UA value reduction of the combined LNG heat exchangers, i.e. if the processes efficiency is held constant when the processes are modified.

Assuming that the pinch is located at the end of the LNG heat exchangers simplifies the optimization work, and has been applied in previous work where MFC systems have been manually optimized directly in HYSYS. This study shows that this modelling assumption has a large impact on optimal MR concentrations, and results in a $2.0 \%-4.0 \%$ increase in energy consumption. Defining external temperature pinches as in Case $A^{*}$ is therefore not recommended. 


\section{Notes}

This research did not receive any specific grant from funding agencies in the public, commercial, or not-for-profit sectors.

\section{REFERENCES}

[1] Pereira C, Lequisiga D. Technical evaluation of C3-MR and cascade cycle on natural gas liquefaction process. International Journal of Chemical Engineering and Applications. 2014;5(6):4516.

[2] Hatcher P, Khalilpour R, Abbas A. Optimisation of LNG mixed-refrigerant processes considering operation and design objectives. Computers \& Chemical Engineering. 2012;41:123-33.

[3] Statoil. Konsekvensutredning Snøhvit LNG. 2001.

[4] Jackson S, Eiksund O, Brodal E. Impact of Ambient Temperature on LNG Liquefaction Process Performance: Energy Efficiency and $\mathrm{CO} 2$ Emissions in Cold Climates. Industrial \& Engineering Chemistry Research. 2017;56(12):3388-98.

[5] de Gouw JA, Parrish DD, Frost GJ, Trainer M. Reduced emissions of CO2, NOx, and SO2 from U.S. power plants owing to switch from coal to natural gas with combined cycle technology. Earth's Future. 2014;2(2):75-82.

[6] Mehrpooya M, Hossieni M, Vatani A. Novel LNG-Based Integrated Process Configuration Alternatives for Coproduction of LNG and NGL. Industrial \& Engineering Chemistry Research. 2014;53(45):17705-21.

[7] Ding H, Sun H, Sun S, Chen C. Analysis and optimisation of a mixed fluid cascade (MFC) process. Cryogenics. 2017;83:35-49.

[8] Qyyum MA, Ali W, Long NVD, Khan MS, Lee M. Energy efficiency enhancement of a single mixed refrigerant LNG process using a novel hydraulic turbine. Energy. 2018;144:968-76.

[9] Jensen JB, Skogestad S. Optimal operation of a mixed fluid cascade LNG plant. In: Marquardt W, Pantelides C, editors. Computer Aided Chemical Engineering: Elsevier; 2006. p. 1569-74.

[10] Kemp IC. Pinch Analysis and Process Integration (Second Edition). Oxford: ButterworthHeinemann, 2007.

[11] Aspelund A, Gundersen T, Myklebust J, Nowak MP, Tomasgard A. An optimization-simulation model for a simple LNG process. Computers \& Chemical Engineering. 2010;34(10):1606-17.

[12] Qyyum MA, Qadeer K, Lee M. Comprehensive Review of the Design Optimization of Natural Gas Liquefaction Processes: Current Status and Perspectives. Industrial \& Engineering Chemistry Research. 2018;57(17):5819-44.

[13] Khan MS, Karimi IA, Wood DA. Retrospective and future perspective of natural gas liquefaction and optimization technologies contributing to efficient LNG supply: A review. Journal of Natural Gas Science and Engineering. 2017;45:165-88.

[14] He T, Karimi IA, Ju Y. Review on the design and optimization of natural gas liquefaction processes for onshore and offshore applications. Chemical Engineering Research and Design. 2018;132:89-114.

[15] Mehrpooya M, Omidi M, Vatani A. Novel mixed fluid cascade natural gas liquefaction process configuration using absorption refrigeration system. Applied Thermal Engineering. 2016;98:591-604. [16] Austb $\varnothing$ B. Use of optimization in evaluation and design of liquefaction processes for natural gas. http://hdl.handle.net/11250/280210: NTNU, 2015.

[17] Ghorbani B, Hamedi M-H, Amidpour M, Mehrpooya M. Cascade refrigeration systems in integrated cryogenic natural gas process (natural gas liquids (NGL), liquefied natural gas (LNG) and nitrogen rejection unit (NRU)). Energy. 2016;115:88-106.

[18] Ghorbani B, Shirmohammadi R, Mehrpooya M. A novel energy efficient LNG/NGL recovery process using absorption and mixed refrigerant refrigeration cycles - Economic and exergy analyses. Applied Thermal Engineering. 2018;132:283-95.

[19] Mokarizadeh Haghighi Shirazi M, Mowla D. Energy optimization for liquefaction process of natural gas in peak shaving plant. Energy. 2010;35(7):2878-85. 
[20] Khan MS, Lee M. Design optimization of single mixed refrigerant natural gas liquefaction process using the particle swarm paradigm with nonlinear constraints. Energy. 2013;49:146-55.

[21] He T, Ju Y. A novel conceptual design of parallel nitrogen expansion liquefaction process for small-scale LNG (liquefied natural gas) plant in skid-mount packages. Energy. 2014;75:349-59.

[22] Chang H-M. A thermodynamic review of cryogenic refrigeration cycles for liquefaction of natural gas. Cryogenics. 2015;72:127-47.

[23] Austbø B, Løvseth SW, Gundersen T. Annotated bibliography-Use of optimization in LNG process design and operation. Computers \& Chemical Engineering. 2014;71:391-414.

[24] Nelder JA, Mead R. A Simplex Method for Function Minimization. The Computer Journal. 1965;7(4):308-13.

[25] Kennedy J, Eberhart R. Particle swarm optimization. Conference Particle swarm optimization, vol. 4. p. $1942-8$ vol.4. 